(REVIEW ARTICLE)

\title{
Occupational exposures and women reproductive health
}

\author{
Singh Zorawar ${ }^{1}$, Randhawa Jasjit Kaur ${ }^{1,}{ }^{*}$ and Kaur Sarabjit ${ }^{2}$ \\ ${ }^{1}$ Department of Zoology, Khalsa College, Amritsar 143001, Punjab, India. \\ 2 G.E.S., Kot Khalsa, Block: Verka, Amritsar 143001, Punjab, India.
}

Publication history: Received on 01 Octoer 2019; revised on 08 November 2019; accepted on 10 November 2019

Article DOI: https://doi.org/10.30574/gscarr.2019.1.1.0005

\begin{abstract}
Occupational exposures in different industries may pose serious health impacts. A number of epidemiological studies have focused on the association of these occupational exposures and adverse health effects. The need of the hour is to focus on the reproductive health of female workers working at different jobs in varied industries. Increasing environmental as well as occupational exposures have led to serious effects on the reproductive health of women and have also endangered the life of future generations. The present paper attempts to focus the impacts of occupational exposures on female reproductive health. Future health based researches are recommended so as to assess the impact of occupational exposures on reproductive capabilities of women workers in different industries.
\end{abstract}

Keywords: Women workers; Reproductive health; Occupational exposures; Pregnancy; Workplace; Smoking

\section{Introduction}

Women health is a priority area and various studies have been done so far [1-4]. Some recent studies also emphasize on different aspects of women health [5-9]. Occupational exposures may lead to serious health impacts [10-14]. Epidemiological studies focusing relation between occupational exposures and adverse reproductive health effects among women are need of the hour. Increasing environmental [15-17] as well as occupational exposures have led not only to an adverse effect [18-25] on the reproductive health of women but also endangered the life of future generations. There is an urgent need to spectate the trends of occupational exposures and their effects in relation to different industries. Early detection of reproductive complications during pregnancy and their timely management are important components of the safe motherhood programme for any of the country.

\section{Pre-conception health and research}

Pre-conception health refers to the health of women during their reproductive years in which they can bear a child. Women workers which are in this period of life may be affected in different ways due to their exposures at their respective workplaces. Researchers have investigated over the different aspects of women reproductive health including depression among infertile women [26]; pelvic inflammatory disease [27]; gonorrhoea and tuberculosis transmission [28]; infertility treatment [29]; HIV infection and sexual behavior [30]; Industrial differences in female fertility treatment rates [31]; fertility preservation in women with breast cancer [32]; Chlamydia [33]; and effect of alcohol and tobacco consumption [34]. Workers who worked in shifts have serious reproductive health issues, the occurrence of abnormal menstruation, reproductive system infection and infertility [35].

\footnotetext{
${ }^{*}$ Corresponding author

E-mail address jaskrandhawa@gmail.com
} 


\section{Effects of different industries}

Plastic chemicals are known to adversely affect reproductive ability [36]. Women workers employed in plastic industries may get affected due to exposures to different sets of chemicals being used. Components used in plastics, such as phthalates, bisphenol A, polybrominated diphenyl ethers and tetrabromobisphenol-A are detected in humans [37]. These endocrine disruptors or thyroid-disrupting chemicals (TDC) are widely used as plastic additives in consumer products which affect reproductive health. Moreover, studies suggest the mixed, significant (alpha $=0.05$ ) TDC associations with natural thyroid hormones [38]. The pregnancy outcome for 305 female plastic welders during 1974-1984 did not show any significant differences with the Swedish average concerning malformation or prenatal mortality [39]. Styrene has been shown to cross the placenta. Some early reports revealed that exposure to styrene can induce spontaneous abortions, menstrual disturbances and congenital malformations. But in more recent studies, no risk was observed among workers exposed to styrene in the reinforced-plastics industry [40-42].

Miners, and those living in communities surrounding mines in developing countries, are vulnerable populations with a high sexual and reproductive health burden [43]. The determinants of reproductive health and quality of life among Indian women in mining communities were examined in a study. A descriptive correlational research design with 145 randomly selected married women in a rural mining region of India was used between January and April 2006. Reproductive health and quality of life was found to be low among Indian women in mining communities. Higher age group, better economic status, higher age at menarche, fewer number of children, absence of long-term illness, reproductive illness and domestic violence were found as important determinants of reproductive health and quality of life among these women [44]. Poor literacy and mobility, low employment and income generating opportunities, poor reproductive health choices and preferences; and poor quality of martial relationships have also been found among women in mining industry [45]. The reproductive profile and frequency of genital infections among women living in the Serra Pelada, a former mining village in the Para state, Brazil was examined. Of the 209 participants, $30 \%$ did not have access to health care services during the preceding year. Risk behaviors included alcohol abuse, 24.4\%; illicit drug abuse, 4.3\%; being a sex worker, 15.8\%; and domestic violence, 17.7\%. Abnormal Pap smear was found in 8.6\%. Prevalence rates of infection were found to be: HIV, 1.9\%; trichomoniasis, 2.9\%; bacterial vaginosis, 18.7\%; candidiasis, 5.7\%; Chlamydial-related cytological changes, 3.3\%; and HPV-related cytological changes, 3.8\% [46].

Distribution of shift work of female workers in different industries and the relationship between shift work and reproductive health was investigated. A cluster sampling questionnaire survey was performed among female workers from 11 industries including electronics, medicine and health, pharmacy from June to September 2016. Usable questionnaires were collected, resulting in a response rate of $96.94 \%$. Workers worked in shifts, accounting for $21.26 \%$, the highest proportion was in the medical industry $30.61 \%$, metallurgy $30.81 \%$, petrochemical engineering $26.78 \%$ respectively. Workers who worked in shifts had significantly higher rate of abnormal menstruation, rate of reproductive system infection in married workers and the rate of infertility as compared with the workers who did not work in shifts [35]. Another study investigated the status of reproductive health among the female medical staff in a provincial maternal and child health hospital to provide a scientific basis for developing related intervention measures and promoting the reproductive health of professional females. The study analyzed the occupational influencing factors for reproductive health, particularly the effects of high-intensity work, work shift, chemical poisons, and physical and biological factors on reproductive health. A reproductive health questionnaire was designed according to age, type of work, professional title, education level, working hours, working strength, and the reproductive health of female staff. It was used to analyze the current status of reproductive health, occupational hazardous factors and working strength. Out of all respondents, $5.90 \%$ visited the hospital due to infertility, $19.46 \%$ had a history of miscarriage, $21.31 \%$ had irregular menstruation within the last 3 months and $30.57 \%$ had reproductive system disease. Other observations included night working in $72.28 \%$ of the investigated medical staff, $47.25 \%$ often worked overtime (more than 3 days a week) and $22.27 \%$ worked over 8 hours daily. The study revealed that occupational hazard factors can be avoided by reasonably arranging the work schedule. Creating a supportive environment may also improve the reproductive health of female medical staff [47].

The reproductive health status of female workers was investigated in the machinery industry and to find the effect of workload on their reproductive health. Female mechanical workers $(\mathrm{N}=5732)$ were selected and investigated by the Female Workers' Reproductive Health Questionnaire. The questionnaire was printed by the occupational health and poisoning control institute of China. The study collected the required information about the reproductive health status of workers from March to December, 2016. The rate of abnormal menstruation was 27.15\%, and the rate of gynecological diseases of female workers was $34.39 \%$. The menstruation abnormality and gynecological diseases rate of female workers with high workload was higher than that female workers with low workload (both p<0.01) [48]. Another study investigated reproductive health status of female workers engaged in administrative management, and to provide a reference for protecting the reproductive health of female workers. A cross-sectional survey was performed 
for 2717 female workers, aged 18-60 years and engaged in administrative management from 13 cities and provinces in China. A questionnaire was used to investigate their general information, occupational hazards in workplace, and reproductive health status, and the reproductive health status of female workers was analyzed. Of all 2717 female workers, 1170 had gynecological diseases or symptoms, resulting in an incidence rate of $43.06 \%$, and among these workers, $11.15 \%$ had abnormal menstruation, 34.64\% had infertility, and 38.76\% had a history of abortion [49]. In a study on female migrant farmworkers in Mendoza, the results showed that the work processes impacting their health include both employment and reproductive labor, and describe the harm, diseases, and illnesses linked to combined work in farms, factories and homes [50].

\section{Effect of alcohol intake and smoking}

Alcohol intake, smoking and tobacco consumption is also up surging among women workers in developing countries with women becoming addicts. This puts a negative impact on their social relationship, financial status and reproductive as well as overall health. Tobacco is responsible for more than 50 percent of the cancers. Apart from this it can also aggravate the problem of low birth weight, stillbirths and miscarriages. There is a dire need for research in the field of reproductive health of women so that they may not face cultural hate.

\section{Conclusion}

Occupational exposures may impose serious health impacts in different industries. Increasing environmental as well as occupational exposures have been reported to seriously affect the reproductive health of women and have endangered the life of future generations. Researchers have investigated over different aspects of women reproductive health including depression among infertile women, pelvic inflammatory disease, gonorrhoea, infertility treatment, HIV infection, sexual behavior and fertility preservation. Other problems faced by women workers include menarche related conditions, fewer number of children, reproductive illness. Alcohol intake and tobacco addiction aggravates the problem of low birth weight, stillbirths and miscarriages. Conclusively, occupational health and safety studies should be undertaken in future to safeguard reproductive health of women workers.

\section{Compliance with ethical standards}

\section{Disclosure of conflict of interest}

The authors declare that they have no competing interest.

\section{References}

[1] Reulecke S, Charleston-Villalobos S, Voss A, Gonzalez-Camarena R, Gaitan-Gonzalez M, Gonzalez-Hermosillo J, Hernandez-Pacheco G and Corrales TA. (2018). Cardiovascular variability in young male and female subjects in health and orthostatic intolerance. Conf Proc IEEE Eng Med Biol Soc, 2957-2960.

[2] Amorosi M. (2018). Ecosustainibility and Mental Health: female aspects. Psychiatr Danub, 30, $431-435$.

[3] Lattof SR, Coast E and Leone T. (2018). Priorities and Challenges Accessing Health Care Among Female Migrants. Health Serv Insights.

[4] Savul S, Naeem Z and Naseem S. (2018). Satisfaction of Female Patients with Health Care Services at the Periurban Community Health Centre in Islamabad. Cureus, 10, e3101.

[5] Wang PY, Chen KL, Yang SY and Lin PH. (2019). Relationship of sleep quality, smartphone dependence, and health-related behaviors in female junior college students. PLoS One, 14, e0214769.

[6] Dekel R, Shaked O, Ben-Porat A and Itzhaky H. (2019). The Interrelations of Physical and Mental Health: SelfRated Health, Depression, and PTSD Among Female IPV Survivors. Violence Against Women.

[7] Rakhshani F, Moghaddam AA, Shahraki-Sanavi F, Mohammadi M and Fakhrerahimi S. (2018). Understanding Female Students' Needs to Develop Health Promoting School Programme: An Exploratory Qualitative Analysis. Malays J Med Sci, 25, 82-94.

[8] Tyler N, Miles HL, Karadag B and Rogers G. (2019). An updated picture of the mental health needs of male and female prisoners in the UK: prevalence, comorbidity, and gender differences. Soc Psychiatry Psychiatr Epidemiol. 
[9] Kivumbi A, Byansi W, Ssewamala FM, Proscovia N, Damulira C and Namatovu P. (2019). Utilizing a family-based economic strengthening intervention to improve mental health wellbeing among female adolescent orphans in Uganda. Child Adolesc Psychiatry Ment Health, 13-14.

[10] Singh Z. (2014). Cancer Occurrence among Textile Industry Workers: Vital Statistics. Int J Ana Pharm Biomed Sci, 3, $5-11$.

[11] Singh Z and Chadha P. (2015). Assessment of DNA Damage as an Index of Genetic Toxicity in Welding Microenvironments among Iron Based Industries. Tox Ind Health, 32, 1817-1824.

[12] Singh Z. (2015). Health Status among Textile Industry Workers: Prevalence and Socioeconomic Correlates of Different Health Problems . Pub Health Prev Med, 1, 137-143.

[13] Singh Z and Bhalla S. (2017). Toxicity of Synthetic Fibres \& Health. Adv Res Tex Eng, 2, 1012-1015.

[14] Singh Z. (2017). Inhalation Toxicity of Graphene and its Derivatives. Inhalation, 11, 20-24.

[15] Singh Z and Randhawa JK. (2014). Assessment of DNA Damage in People Living Near Textile Industries by Comet Assay. Biosci int, 3, 1-5.

[16] Singh Z, Singh J, Udesha, Bath KS and Shama NG. (2015). Assessment of Total Iron Content in Scalp Hair Samples of People Living in the Vicinity of Hudiara Drain, Amritsar, Punjab. Eur J Biomed Pharm Sci, 2, 519-527.

[17] Singh Z, Kaur J, Kaur R and Hundal SS. (2016). Toxic Effects of Organochlorine Pesticides: A Review. American J BioSci, 4, 11-18.

[18] Chadha P, Ahmed G and Singh Z. (2012). Genotoxic Biomonitoring of Human Population Exposed to Pesticides. J Exp Zoology India, 16, 239-244.

[19] Singh Z and Chadha P. (2014). DNA Damage Due to Inhalation of Complex Metal Particulates among Foundry Workers. Adv Env Biol, 8, 225-230.

[20] Singh Z and Chadha P. (2016). Lung Health among Welders. American J Env Occu Health, 1, 6-10.

[21] Singh Z. (2016). Textile Industry and Occupational Cancer. J Occu Med Tox, 11, 39-44.

[22] Singh Z and Chadha P. (2012). Health Concerns in Welding Industry. Int J Enh Res Sci Tech Eng, 2, 1-5.

[23] Singh Z, Chadha P and Sharma S. (2013). Evaluation of Oxidative Stress and Genotoxicity in Battery Manufacturing Workers Occupationally Exposed to Lead. Tox Int, 20, 95-100.

[24] Singh Z and Chadha P. (2013). Oxidative Stress Assessment among Iron Industry Grinders. Biochem Cell Arch, 12, 65-68.

[25] Singh Z and Chadha P. (2013). Assessment of Genotoxic Effect of Fibre Dust among Textile Industry Workers. J Env Sci Sust, 1, 81-84.

[26] Alhassan A, Ziblim AR and Muntaka S. (2014). A survey on depression among infertile women in Ghana. BMC Womens Health, 14, 42.

[27] Bhurt AW, Fikree FF, Bhurt AM, Channa GZ, Soomro RA and Bhurt N. (1999). Prevalence and risk factors of symptoms of pelvic inflammatory disease in a rural community of Jamshoro, Sindh, Pakistan. J Pak Med Assoc, 49, 188-194.

[28] Cassels S and Singer BH. (2010). Population decline induced by gonorrhoea and tuberculosis transmission: Micronesia during the Japanese occupation, 1919-45. J Popul Res (Canberra ), 27, 293-313.

[29] Donkor ES and Sandall J. (2009). Coping strategies of women seeking infertility treatment in southern Ghana. Afr J Reprod Health, 13, 81-93.

[30] Favot I, Ngalula J, Mgalla Z, Klokke AH, Gumodoka B and Boerma JT. (1997). HIV infection and sexual behaviour among women with infertility in Tanzania: a hospital-based study. Int J Epidemiol, 26, 414-419.

[31] Feveile H, Schmidt L, Hannerz H and Hougaard KS. (2011). Industrial differences in female fertility treatment rates--a new approach to assess differences related to occupation? Scand J Public Health, 39, 164-171.

[32] Lee S, Heytens E, Moy F, Ozkavukcu S and Oktay K. (2011). Determinants of access to fertility preservation in women with breast cancer. Fertil Steril, 95, 1932-1936.

[33] Macmillan S, Walker R, Oloto E, Fitzmaurice A and Templeton A. (1999). Ignorance about Chlamydia among sexually active women--a two centre study. Hum Reprod, 14, 1131-1135. 
[34] Weigel MM and Weigel RM. (19880. The association of reproductive history, demographic factors, and alcohol and tobacco consumption with the risk of developing nausea and vomiting in early pregnancy. Am J Epidemiol, 127, 562-570.

[35] Yu CY, Yu WL, Xu M and Xing ZL. (2018). Investigation and Analysis on shift work female workers' and the impact on reproductive health. Zhonghua Lao Dong Wei Sheng Zhi Ye Bing Za Zhi, 36, 126-129.

[36] Hougaard KS, Hannerz H, Feveile H and Bonde JP. (2009). Increased incidence of infertility treatment among women working in the plastics industry. Reprod Toxicol, 27, 186-189.

[37] Talsness CE, Andrade AJ, Kuriyama SN, Taylor JA and vom Saal FS. (2009). Components of plastic: experimental studies in animals and relevance for human health. Philos Trans R Soc Lond B Biol Sci, 364, 2079-2096.

[38] Andra SS and Makris KC. (2012). Thyroid disrupting chemicals in plastic additives and thyroid health. J Environ Sci Health C Environ Carcinog Ecotoxicol Rev, 30, 107-151.

[39] Kolmodin-Hedman B, Hansson MK, Hagberg M, Jonsson E, Andersson MC and Eriksson A. (1988). Health problems among operators of plastic welding machines and exposure to radiofrequency electromagnetic fields. Int Arch Occup Environ Health, 60, 243-247.

[40] Lindbohm ML. (1993). Effects of styrene on the reproductive health of women: a review. IARC Sci Publ, 163-169.

[41] Harkonen H and Holmberg PC. (1982). Obstetric histories of women occupationally exposed to styrene. Scand J Work Environ Health, 8, 74-77.

[42] Kosmiderski S. (1968). [Use of styrene latex of domestic production for the in vitro tests of gonadotropin detection in the urine of pregnant women]. Ginekol Pol, 39, 457-461.

[43] Dawson AJ and Homer CS. (2013). How does the mining industry contribute to sexual and reproductive health in developing countries? A narrative synthesis of current evidence to inform practice. J Clin Nurs, 22, 3597-3609.

[44] D'Souza MS, Somayaji G and Subrahmanya NK. (2011). Determinants of reproductive health and related quality of life among Indian women in mining communities. J Adv Nurs, 67, 1963-1975.

[45] D'Souza MS, Karkada SN, Somayaji G and Venkatesaperumal R. (2013). Women's well-being and reproductive health in Indian mining community: need for empowerment. Reprod Health, 10-24.

[46] Miranda AE, Mercon-de-Vargas PR, Corbett CE, Corbett JF and Dietze R. (2009). Perspectives on sexual and reproductive health among women in an ancient mining area in Brazil. Rev Panam Salud Publica, 25, $157-161$.

[47] Lv X, Wang XH, Wu L, He WJ and Xia JH. (2018). [Current status of reproductive health and its occupational influencing factors among female medical staff in a provincial maternal and child health hospital]. Zhonghua Lao Dong Wei Sheng Zhi Ye Bing Za Zhi, 36, 419-421.

[48] Liu J, Yu WL, Xia Q, Zhao TT, Pan LP, Zhang HD, Zhou P and Song HY. (2018). [Effects of Workload on Reproductive Health Status of Female Workers in Mechanical Manufacturing Industry]. Zhonghua Lao Dong Wei Sheng Zhi Ye Bing Za Zhi, 36, 416-418.

[49] Ling YL, Mei LY, Wei TT, Zhang LL, Lu L and Yu WL. (2018). [An investigation of reproductive health in female workers engaged in administrative management]. Zhonghua Lao Dong Wei Sheng Zhi Ye Bing Za Zhi, 36, 288291.

[50] Linardelli MF. (2018). [Among the farm, the factory, and home: productive and reproductive work of female migrant farmworkers in Mendoza (Argentina) and its impact in the health-disease process]. Salud Colect, 14, 757777.

\section{How to cite this article}

Singh Z, Randhawa JK and Kaur S. (2019). Occupational exposures and women reproductive health. GSC Advanced Research and Reviews, 1(1), 26-30. 